\title{
El rol de las fórmulas de tratamiento en blogs y foros religiosos: hacia una horizontalidad dialógica digital
}

The role of address forms in blogs and religious forums: towards a digital dialogical horizontality

\section{Magaly Varas}

Pontificia Universidad Católica de Valparaíso

Chile

\section{Liliana Vásquez-Rocca}

Pontificia Universidad Católica de Valparaíso

Chile

Número especial

- IV -

Apelación en el discurso digital

2018
ONOMÁZEIN - Número especial IV: Apelación en el discurso digital (octubre de 2018): 70-97 DOI: 10.7764/onomazein.add.03

ISSN: 0718-5758

\section{(c) $\underset{\substack{\mathrm{ar} \\ \mathrm{ar}} \mathrm{No}}{\mathrm{Na}}$}

Magaly Varas: Pontificia Universidad Católica de Valparaíso, Chile.

| Correo electrónico: magalyvaras@gmail.com

Liliana Vásquez-Rocca: Pontificia Universidad Católica de Valparaíso, Chile.

| Correo electrónico: I_rocca@hotmail.com 


\section{Resumen}

Las nuevas prácticas discursivas digitales, eminentemente dialógicas, presentan un desafío para los discursos verticales, los que se definen por tener una voz poseedora de un saber privilegiado que envía información a un grupo receptor pasivo. Uno de los más prototípicos de estos es el discurso religioso, que tradicionalmente se ha caracterizado por que el locutor es una voz autorizada y autoritaria, quien se apropia de la voz de Dios, restringiendo el intercambio comunicativo, lo que pone de manifiesto la forma en que se ejerce el poder entre los participantes, es decir, determina una relación asimétrica de cercanía. El nuevo espacio público virtual permite la configuración de mecanismos discursivos interactivos en el discurso religioso posiblemente diferentes a los medios tradicionales, por lo que buscamos describir las relaciones de poder y solidaridad, y el uso de la palabra autoritaria que denotan las fórmulas de tratamiento (mecanismos apelativos) que se utilizan en el discurso religioso digital de dos credos (protestante y católico) a través de una metodología mixta que integra elementos cuantitativos con la visión cualitativa. Tras el análisis, los hallazgos indican una tendencia hacia una comunicación más horizontal que podría estar dada por dos razones: la primera está anclada en la participación más activa de los fieles en la construcción y mantención de creencias, interacción que tiende a velar la voz autorizada, y la segunda es que podría ser una consecuencia del tipo de plataforma, aunque el foro posibilitaría una comunicación más horizontal que el blog.

Palabras clave: discurso religioso digital; voz autorizada; poder simbólico; fórmulas de tratamiento; comunicación horizontal.

\section{Abstract}

New digital discursive practices, mainly dialogical, present a challenge to the vertical discourses, where the voice with power of a privileged knowledge sends information to a passive receptor group. One of the most prototypical discourses is the religious one, that traditionally has been characterized by the fact that the locutor is an authorized and authoritarian voice, who appropriates the voice of God restricting the communicative exchange, that shows the way in which the power is performed between the participants. The new virtual public space allows the configuration of interactive discursive mechanisms in religious discourse possibly 
different from traditional media, therefore we seek to describe the relations of power and solidarity, and the use of the authoritarian word that denote the forms of address (appealing mechanisms) that are used in the digital religious discourse of two creeds (Protestant and (atholic) through a mixed methodology that integrates quantitative elements with the qualitative vision. After the analysis, the findings indicate a more horizontal communication, that could be given for two reasons: the first, because there is more active participation of the believer in the construction and maintenance of beliefs, interaction that tends to guard the authorized voice, and the second is that it could be a consequence of the type of platform, although the forum would enable a more horizontal communication than the blog.

Keywords: digital religious discourse; authorized voice; symbolic power; forms of address; horizontal communication. 


\section{Introducción}

El discurso religioso ha sido caracterizado principalmente por ser autoritario (Orlandi, 1987, 1996, 2012; Faye, 2007; Da Silva y Costa, 2011), es decir, en él existe una restricción en la relación dialógica más acentuada entre los interlocutores, lo que proporciona la instauración de condiciones para el ejercicio de dominación de un individuo sobre otro. Orlandi (1987) precisa que es un ejemplo de la manifestación en la que predomina el mecanismo del autoritarismo discursivo. Además de este rasgo vertical del discurso religioso, según Bajtín (2011), la palabra del tipo autoritaria se impone más allá de su grado de persuasión, por ser reconocida y asimilada por quienes la escuchan o leen. Por su parte, Maingueneau y Cossutta (1995) consideran al discurso religioso como del tipo constitutivo, en el sentido de que tiene calidad de fundador, y, por tanto, niega la interacción o pretende someterla a ciertos principios impuestos. Este tipo de discurso ha sido estudiado principalmente en géneros religiosos tradicionales como el sermón, los textos bíblicos, las encíclicas que circulan en soportes relativamente estables, tanto orales como escritos (e. g., Acebal, 2002, 2006; Vitale, 2003; Arnoux, 2004 Bonnin, 2006, 2010).

En los últimos 20 años, el discurso religioso ha tenido que migrar, como otras instituciones, paulatinamente hacia Internet, un dispositivo material que se caracteriza por construir un nuevo espacio público virtual, cuyo rasgo principal es el de la interactividad comunicativa (Rost, 2004; Scolari, 2008; Varas y González, 2016). Esta plataforma ha planteado un verdadero desafío para el locutor religioso, principalmente porque la comunicación, que antes de la irrupción de Internet era más bien vertical, constituida por "receptores que eran pasivos de las verdades creadas y enviadas desde lo alto, por quienes controlan y poseen la información y tienen el poder de enviar e instalar sus verdades" (Tolosa, 2011), ha pasado a ser cada vez más horizontal, plano en el que la figura autoritaria es desdibujada, tomando mayor protagonismo los interactuantes del discurso (Tolosa, 2013).

Un ejemplo particular del tipo de prácticas discursivas que se encuentran en Internet es el que se produce en los blogs y los foros. En estas plataformas, un interlocutor presenta una duda, una experiencia, un problema, entre otros, lo que abre un debate en el que cualquier persona puede comentar gracias a que la instancia así lo permite. De este modo, se forman muchas veces verdaderas conversaciones virtuales que al permanecer en línea siguen creciendo incluso durante años. En el ámbito del discurso religioso existen algunas experiencias de blogs y foros en los que se plantean diversos temas doctrinales propios de la actualidad. De acuerdo a una revisión previa realizada por las autoras tanto en blogs como en foros con el objetivo de describir y comparar expresiones metafóricas y modalidad del enunciado en los discursos utilizados por tres credos religiosos — católicos, protestantes y Testigos de Jehová- a través del análisis de contenido, Ios tópicos de mayor preferencia -en cuanto a la cantidad de comentarios observados - son aquellos que refieren a las relaciones de pareja y la sexualidad. El alto interés por estos tópicos podría deberse a que, según las Escrituras, el no cumplir con sus preceptos respecto al lugar que ocupa el cuerpo en la vida del ser humano 
impide alcanzar a Dios (Eliade, 1998), razón por la cual se busca consejo y guía mediante estas instancias virtuales.

Por lo anterior, en este artículo damos cuenta específicamente de este tipo de interacciones (en blog y foro de temas de pareja y sexualidad) porque nos interesa observar la manera en que los credos religiosos manejan la palabra autoritaria en un espacio público virtual que tiene sus propios condicionamientos técnicos, discursivos y doctrinarios. En estas expresiones verbales que emiten los participantes, la mayoría anónimos o con nombres simulados, es posible encontrar diversas fórmulas de tratamiento, elementos que denotan la manera en que se establece la relación entre los interactuantes, por lo que serán el foco de nuestra investigación. En este sentido, nos adscribimos a la definición amplia e integral de fórmulas de tratamiento de Rigatuso (2009) que expondremos más adelante. Asimismo, realizamos nuestro análisis complementando la teoría del poder y solidaridad de Brown y Gilman (1960) con la noción de poder pastoral de Foucault (2008, 2009, 2011); esta última apoya la comprensión de cómo se evidencia el poder en la interacción entre dos individuos en una sociedad a partir de la observación y análisis de las fórmulas de tratamiento.

En este contexto, el objetivo de esta investigación es describir las relaciones de poder y solidaridad, y el uso de la palabra autoritaria que los mecanismos apelativos utilizados en el discurso religioso digital denotan, a través del análisis de las fórmulas de tratamiento utilizadas por los participantes de blogs y foros de dos credos religiosos (católicos y protestantes). El estudio de estas formas discursivas es relevante, sobre todo considerando que estos nuevos dispositivos cuentan con herramientas de diálogo que el discurso religioso tradicional (sermones, encíclicas, textos bíblicos, folletos, boletines) no incluye.

En términos de estructura, en la primera parte de este artículo se describe el discurso religioso como del tipo autoritario (Orlandi, 1996; Bajtín, 2011), en el cual se ejerce el poder pastoral (Foucault, 2008, 2009, 2011) y que puede considerarse constituyente de otras formas de discursos (Maingueneau y Cossutta, 1995). Luego, se explica el fenómeno del discurso religioso digital, en particular el blog y el foro (Gouti, 2006; Martínez, 2007; Pano, 2008, 2009; Tolosa, 2011) como plataformas de géneros emergentes que plantean un nuevo desafío para las religiones (De Souza, 2014). A continuación, se expone la concepción de las fórmulas de tratamiento como mecanismos apelativos (Rigatuso, 2000, 2006, 2009, 2011), en los que es posible observar el poder/solidaridad y cercanía/distancia que se ejerce en los credos en las diversas interacciones discursivas (Brown y Gilman, 1960). Posteriormente, se presenta la metodología mixta utilizada y los hallazgos que nos llevan a las conclusiones presentadas para esta investigación.

\section{2. ¿Cómo se ha caracterizado el discurso religioso?}

El discurso religioso ha sido descrito como de tipo autoritario (Orlandi, 1987, 1996, 2012; Faye, 2007; Da Silva y Costa, 2011), es decir, es aquel en que "la polisemia es contenida, el referente 
está borrado por la relación de lenguaje que se establece y el locutor se coloca como agente exclusivo, borrando también su relación con el interlocutor" (Orlandi, 2012: 91). De acuerdo a Bajtín (2011), la palabra autoritaria religiosa, por su naturaleza, exige ser reconocida y asimilada. Se trata de una palabra preexistente, de los antepasados, que entra en la conciencia verbal como un todo compacto a la que no se puede modificar, se acepta o rechaza por completo, lo que significa que está unida a la autoridad que puede ser una institución, una persona o un poder político.

Adicionalmente, Maingueneau y Cossutta (1995) consideran al discurso religioso como del tipo constitutivo, es decir, tiene la calidad de ser fundador de los demás discursos y está asociado a un cuerpo de enunciadores consagrados y a una memoria que es aceptada y validada por la sociedad, como, por ejemplo, el discurso de la filosofía, el discurso científico y el discurso religioso. En este sentido, este último pretende someter a la sociedad a los principios que sus fundadores han construido y que se imponen y aceptan sin discusión, por lo que afecta también la interacción.

Este discurso religioso, tradicionalmente vertical y autoritario, es descrito por Foucault (2008, 2009, 2011) a través de la noción de poder pastoral. En un sentido general, para el autor el fenómeno del poder es el efecto de las asimetrías entre los sujetos que están presentes en todas las rejillas de la sociedad. Siempre está asociado a una relación dual en que uno ejerce poder sobre otro, como, por ejemplo, cuando el sacerdote recibe la confesión de un pecador, o el maestro enseña al estudiante, o el policía detiene al delincuente. Es justamente esto lo que sucede en el discurso religioso: la voz autorizada establece los tópicos y las verdades de cada credo, ya que tiene el poder de imponer y sofocar otras verdades posibles. El poder pastoral "es un poder de tipo religioso que tiene su principio, su fundamento y su perfección en el poder que Dios ejerce sobre su pueblo" (Foucault, 2009: 153). Es este poder en el discurso religioso el que produce una restricción de los intercambios comunicativos en el que predomina la voz del representante de Dios por sobre otros feligreses.

\subsection{La migración del discurso religioso hacia el entorno digital}

Ahora bien, Internet surge alrededor de 20 años atrás en nuestras sociedades. Esta red comunicativa ha atraído de tal manera a las personas que tienen acceso a ella que la mayoría de las instituciones y organizaciones humanas se han visto obligadas a migrar sus discursos hacia este nuevo espacio de interacción, siguiendo a sus audiencias (Vilches, 2001).

En este contexto del surgimiento de las plataformas comunicativas digitales, uno de los fenómenos más destacados ha sido la nueva forma en que está fluyendo la información y, por tanto, la comunicación. Esto quiere decir que en la web se presenta una infraestructura de la cual es posible apropiarse y en la cual la mayor parte del contenido puede ser construido por 
Ios usuarios (Androutsopoulos, 2010). En este sentido, de acuerdo a Tolosa (2011), antes del surgimiento de las plataformas digitales los receptores eran más bien pasivos de las verdades que enviaban aquellos que controlaban la información. Sin embargo, el autor señala que el panorama ha cambiado porque hoy en día

las instituciones, las más grandes y las más pequeñas están sometidas al escrutinio y la duda constante, desde la empresa hasta la familia, desde la Iglesia hasta los medios de comunicación, desde el gobierno hasta las organizaciones sindicales. La pérdida del poder de emisión casi exclusivo de los líderes junto al potenciamiento de la capacidad expresiva de las comunidades están transformando el escenario (Tolosa, 2013: 114).

El autor agrega que la conservación del poder y del mundo que rige las principales organizaciones está siendo amenazada de forma implícita o explícita por este nuevo orden mundial, en el que las fronteras se diluyen y las conversaciones se multiplican.

Junto con las redes sociales, las plataformas más populares y preferidas por los usuarios de la web son los foros y los blogs, dos modalidades de interacción comunicativa digital que han tenido un gran auge en estos últimos años. En la actualidad, tanto foros como blogs coexisten y muchas veces se complementan de acuerdo a las necesidades de comunicación de sus usuarios.

Los foros fueron creados para debatir temas partiendo de una pregunta inicial, duda o inquietud de un usuario, por lo que la participación de los que se interesan en resolver dicha consulta es muy relevante para el funcionamiento del foro. Según Pano (2008), los foros son dispositivos híbridos de comunicación interpersonal de masas que se han difundido ampliamente gracias a que han sido empleados por medios de comunicación y otros organismos sociales, en forma complementaria. De acuerdo con la autora, "suelen estar moderados por un alguien que introduce el tema de la discusión, formula la primera pregunta, estimula y otorga la palabra, pide explicaciones y sintetiza lo expuesto antes de cerrar la discusión” (Pano, 2008: 143).

Según Gouti (2006), el foro cuenta con un canal de transmisión escrito porque el participante produce enunciados concretos, pero, a la vez, la situación de comunicación es oral, ya que se observa un sistema de turnos como en una conversación, así como otros elementos paraverbales, como signos de puntuación que simulan gestos y emociones. Sin embargo, a diferencia de la oralidad prototípica, los interactuantes no están presentes en este diálogo, sino que se expresa en tiempos diversos (a diferencia, por ejemplo, de un chat). La propiedad "archivable" de estos mensajes que quedan a la espera de comentarios o respuestas permite que puedan ser consultados posteriormente por otros, convirtiéndolos en un espacio público. Finalmente, el autor señala que el propósito principal de un foro es convencer o persuadir, lo cual lo sitúa dentro del modo argumentativo, convirtiendo el diálogo en una discusión más que en una conversación. 
Por su parte, el objetivo del blog es más personal, ya que parte de un texto en el que una persona (o grupo) entrega su punto de vista sobre un tema o comparte sus experiencias con los demás. Mediante el diálogo que se produce gracias a las cajas de texto publicables que se agregan al final del blog, este favorece la creación de comunidades de autores y de lectores, amplias o restringidas, en función del tema, del tipo de relación que se establece entre los usuarios y de la apertura o restricción de las modalidades de participación, las que "dependen, por ejemplo, del interfaz, de la temática (más o menos polémica), del carácter general o especializado del blog" (Pano, 2009: 19).

De acuerdo a Martínez (2007), "en el blog sólo hay un protagonista, es el Ilamado 'espacio personal'”, quien crea un espacio dialéctico virtual, en el cual se generan verdaderas conversaciones muchas veces con interlocutores completamente desconocidos. Martínez (2007) agrega que las funciones comunicativas de los posts o entradas que se publican en este tipo de plataformas son dos: demarcar, ya que el autor pretende dar puntos de vista y opiniones sobre un tema, y también una función estética, pues gran parte de los blogs tiene un carácter expresivo, creativo e incluso literario. Cabe destacar, según el autor, la importante función que tienen los hipervínculos dentro de los blogs, que "multiplica, a mi entender, la referencialidad del signo tradicional, en cierta manera, lo actualiza" (Martínez, 2007). La presencia de estos hipervínculos da como resultado lo que se denomina hipertexto, cuya principal característica es el dinamismo. Esto último implica que todos aquellos vínculos presentes generan diversos tipos de lecturas fuera del texto mismo, ya que el usuario podrá conectar a otros escritos tanto dentro blog como fuera de él, de acuerdo a donde lo lleve el hipervínculo.

Ahora bien, para distinguir entre blog y foro en este artículo nos focalizamos en dos aspectos esenciales que consideramos relevantes en nuestra investigación sobre formas de tratamiento utilizadas en estas plataformas: la interacción y el propósito de ambas plataformas. Si pudiéramos ejemplificarlos, el blog es como la cátedra de un profesor destacado, donde la interacción se da más bien desde el docente a sus alumnos, es decir, hay mayor asimetría en la relación. Por su parte, el foro es como un bar, en el cual prácticamente todos tienen la misma jerarquía, lo cual significa que el intercambio y la intención comunicativa en cada plataforma es diferente. En el caso del blog, la interacción es restringida y dirigida por el locutor que propone el tema; por lo tanto, es más bien vertical (del bloguero a su audiencia digital); en cambio, en el foro, la interacción es más horizontal, es decir, todos podrían eventualmente plantear su punto de vista, aun cuando exista un moderador que organiza algunos comentarios, lo cual debilita parcialmente la jerarquía comunicativa en esta plataforma (Orihuela, 2006).

En cuanto al propósito, el blog está destinado a expresar un punto de vista particular del autor o institución que busca convencer a sus participantes; en contraste, en el foro se busca establecer un tema para ser discutido.

Aunque no tan masivamente como en otro tipo de instituciones (gubernamentales, educativas, empresariales, etc.), los credos religiosos no han estado fuera de la amplia prolifera- 
ción de blogs y foros. De este modo, el hecho de que las religiones migren hacia los medios digitales exige una adaptación entre el discurso religioso y el soporte que lo vehicula. Esto es porque, según De Souza (2014), el ciberespacio se presenta como un potencial desafío, ya que la diversidad característica de este medio tiende a ser una amenaza a la trascendencia y a la naturaleza constitutiva del discurso religioso. No obstante, quedarse fuera del contexto mediático, añade, puede significar una pérdida de la legitimación organizacional.

Tal como lo comentamos en la introducción, los tópicos de mayor preferencia (en el sentido de la alta participación de los usuarios) de los blogs y foros religiosos son principalmente aquellos se que refieren a las relaciones de pareja y la sexualidad. De acuerdo a Eliade (1998), desde el punto de vista religioso contemporáneo, cuanto menos sacralizada esté una sociedad, menos santificada está la vida, por lo cual, en este contexto, los actos fisiológicos responderán a una necesidad corporal únicamente instintiva, y, por haberse perdido la dimensión de lo sagrado, no tienen posibilidad de trascendencia. Esta necesidad y búsqueda de sacralización y trascendencia sería la razón por la cual los creyentes preferirían ampliamente estos tópicos, comentando y debatiendo profusamente sobre ellos, con la esperanza de ser aconsejados y guiados nuevamente hacia el camino sacralizado. Es así como se observa que muchas de estas entradas de blogs y foros cuentan con numerosos comentarios e incluso registran varios años de permanencia en la red con activa participación.

En la búsqueda por la adaptación al nuevo espacio virtual, los discursos, incluyendo el religioso, han sufrido una serie de transformaciones: el foro, emulando al debate presencial, emerge como una instancia de carácter híbrido oral-escrito, con un propósito persuasivo y carente de presencia física (Gouti, 2006), y, por su parte, el blog, simulando a la bitácora o al diario de vida, surge como una instancia personal cuyo propósito es a la vez persuasivo y estético; al ser capaces de contener hipervínculos, crean una nueva forma de lectura hipertextual que deja de ser lineal, pasando a ser dinámica (Martínez, 2007). Esto coincide con Crystal (2001), quien ha estudiado chats y correos electrónicos, entre otras formas de diálogo digital, y plantea que hay signos evidentes de variedades del uso del lenguaje en contextos tecnológicos. Estas características emergentes, propias de este nuevo tipo de discurso, están cambiando profundamente la forma en que nos estamos relacionando tanto virtualmente como en la vida real.

En este sentido, nos interesa observar, particularmente, el fenómeno del poder en el discurso religioso digital que se desprende del uso de las fórmulas de tratamiento, tal como veremos en el siguiente apartado.

\section{Fórmulas de tratamiento. Poder y solidaridad}

En el discurso religioso digital pueden observarse múltiples fenómenos lingüístico-discursivos que dan cuenta de las relaciones comunicativas que se establecen entre los interlocuto- 
res. Uno de estos fenómenos son las fórmulas de tratamiento, que según Rigatuso (2000) son "un conjunto de formas que poseen los hablantes de distintas comunidades lingüísticas para dirigirse al destinatario y hacer referencia en el mensaje a una tercera persona y a sí mismos en el discurso" (Rigatuso, 2009: 353-354). Su enfoque pertenece a una perspectiva amplia sobre este fenómeno, es decir, incluye formas vocativas, referenciales y de autorreferencia e implica además su empleo como designación de carácter genérico para aludir a hombres, mujeres y niños, así como a grupos humanos.

La propuesta de Rigatuso sobre las fórmulas de tratamiento (2000, 2009, 2011) permite visualizar la manera en que el uso lingüístico evidencia un proceso sociohistórico, que refleja políticas, culturas y relaciones sociales, además de ser elementos que ponen de manifiesto la identidad de un individuo o bien de un grupo en sus distintos niveles.

Adicionalmente a la concepción de fórmulas de tratamiento de Rigatuso (2009), hemos recogido los planteamientos de Brown y Gilman (1960) en torno a la teoría del poder y la solidaridad. Cabe destacar que el análisis que realizan los autores de las fórmulas de tratamiento corresponde a una situación pretecnológica, enfocándose en el periodo desde la Edad Media, principalmente europea, hasta los años 50 del siglo XX, razón por la cual cobra relevancia observar este fenómeno sociolingüístico a la luz de las nuevas formas de comunicación.

Ahora bien, el planteamiento de los autores propone que el uso de los pronombres de tratamiento estaría regido por dos dimensiones (eje poder/solidaridad y cercanía/distancia) que se desprenden de las relaciones entre los interactuantes en un contexto cultural e histórico determinado; se trata de dimensiones sociolingüísticas vigentes en un determinado núcleo social. Esto daría paso a la conformación de esquemas de uso de pronombres, nombres y formas verbales, y caracterizaría el tipo de relación y jerarquía que explicaría un determinado uso de acuerdo a la relación de cercanía/distancia y de poder/solidaridad que se configure entre los interactuantes. En la figura 1 hemos representado los ejes mencionados utilizando, además, algunos ejemplos para ilustrar cómo estos se han desplazado históricamente de acuerdo con lo planteado por Brown y Gilman (1960).

Los pronombres que derivan de estas relaciones en su uso entre interlocutores permiten observar el poder que una persona detenta por sobre otra de acuerdo al nivel de control que ejerce sobre su comportamiento y al tipo de relación de cercanía/distancia que desarrolla. Por ejemplo, el uso de fórmulas de tratamiento (en adelante, FDT) entre un Padre/Hijo o Sacerdote/Fiel durante la Edad Media estaba marcado por V-T (iniciales de Vous-Tu, del francés), es decir, fórmulas que expresaban principalmente poder y cercanía (el feligrés recibía T [Tu]) del sacerdote y este último recibía $\vee$ [Vous] del feligrés). Respecto a la solidaridad, según Brown y Gilman (1960) en la Edad Media existía una tendencia a usar fórmulas de tratamiento T-T (iniciales de Tu-Tu, del francés), en algún tipo de relaciones acotadas como en el caso de Hermano/Hermano. 


\section{FIGURA 1}

Desplazamiento histórico de las fórmulas de tratamiento. Esquema adaptado de Brown y Gilman (1960)

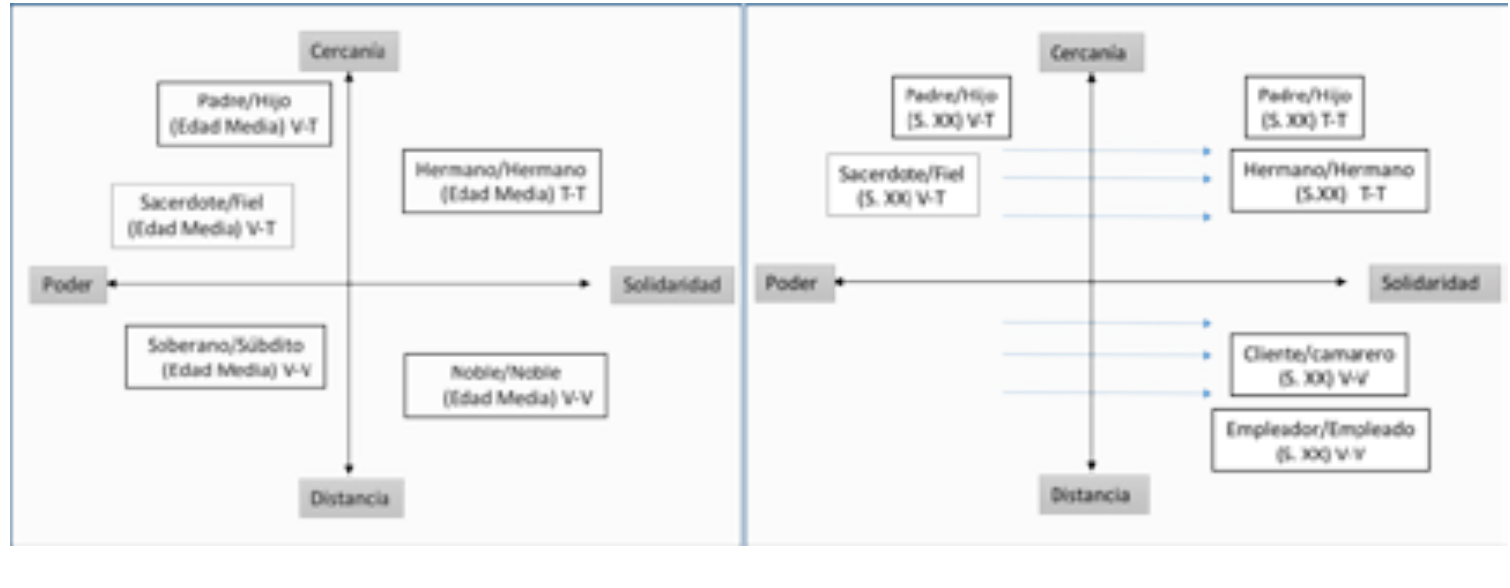

Los autores señalan que al comenzar el siglo XX se habría producido un desplazamiento hacia el uso de fórmulas de tratamiento que denotan solidaridad. Así, las formas de tratamiento que antes eran problemáticas, como T-V o $V$ en las relaciones cliente/camarero o empleador/empleado, tienden a decantar en $V$ solidario, pero de distancia. Por otro lado, hay relaciones que cambian su eje de acción, como, por ejemplo, el del Padre/Hijo, que en el siglo XX tiende hacia la forma de solidaridad T-T. Esto estaría determinado por la jerarquía y por el tipo de relación que existe en un momento histórico, social y cultural entre los que realizan intercambios comunicativos. Por lo anterior, esta teoría de dos dimensiones (poder/solidaridad y cercanía/distancia) permite analizar los usos de fórmulas de tratamiento en diversos contextos sociales, observando si lo que predomina es la dimensión de solidaridad o la de poder.

De acuerdo a lo anterior, el punto central del planteamiento de Brown y Gilman (1960) es que, en su evolución, las fórmulas de tratamiento históricamente han ido desplazándose desde el eje del poder (asimetría en el uso de las FDT) hacia el eje de la solidaridad (simetría en el uso de las FDT), lo que hace que los tratamientos sean más simétricos. Los autores observaron tempranamente que los hablantes comenzaron a escoger mayormente formas de tratamiento de solidaridad. En sus palabras, "the modern direction of change in pronoun usage expresses a will to extend the solidarity ethic to everyone" (1960: 280), por lo cual los pronombres que están predominando son los de esta categoría, por encima de los pronombres asociados al poder, modalidad formal reservada más bien para instancias de distancia comunicativa, cada vez más acotadas.

Si bien han existido varios estudios que plantean diversas maneras de clasificar las fórmulas de tratamiento desde una perspectiva principalmente gramatical (Fontanella, 1999; Edeso, 2005, 2012; Hummel, 2010; Calderón, 2010) hemos escogido a Rigatuso (2000, 2011) y 
Brown y Gilman (1960) porque nos entregan una visión que integra lo pragmático, lo social y lo semántico del uso de las fórmulas de tratamiento.

Lo anterior nos permiten dar cuenta de lo que nos interesa, esto es, observar en el discurso religioso digital cómo las fórmulas de tratamiento manifiestan poder/solidaridad y cercanía/distancia tanto por el representante oficial del credo (bloguero o administrador/ moderador del foro) como por los participantes de este tipo de discurso en nuevos contextos digitales, y cómo se refleja la tendencia histórica señalada por Brown y Gilman (1960), principalmente hacia la solidaridad/cercanía más que hacia el poder/distancia, lo cual indicaría que en este tipo de plataformas el ejercicio del poder se está desplazando y acotando.

Cabe señalar que, en los últimos años, las fórmulas de tratamiento y la (des)cortesía han comenzado a ser estudiadas en entornos digitales, en interacciones mediadas por computador u otro dispositivo electrónico (Cantamutto, 2011; Cautín-Epifani, 2015). Destaca, además, el programa de Estudios del Discurso sobre la Cortesía del Español (EDICE), que ha publicado estudios en esta línea (Ridao, 2014; Placencia, 2015); sin embargo, aún no es posible encontrar investigaciones específicamente sobre fórmulas de tratamiento en blogs y foros para el español.

En cuanto a la propuesta de Brown y Gilman (1960), esta ha sido utilizada para analizar otro tipo de discursos digitales, específicamente en las interacciones producidas a través de Facebook, como en el estudio de Cautín-Epifani (2015), el cual concluyó que prevalece el tratamiento solidario y simétrico. La autora explica estos resultados señalando que la prevalencia del esquema de tratamiento se establece siguiendo la fórmula de tratamiento utilizada por los interactuantes fuera del medio virtual.

Ahora bien, es importante señalar que en la tradición de los estudios sociolingüísticos las formas pronominales "tú” y “usted” suelen tomarse como ejes centrales para la organización de las formas de tratamiento en las comunidades de hablantes del español tanto en España como en Latinoamérica (Hummel, 2010). Estas dos formas pronominales romances han sido utilizadas para manifestar la interacción entre dos hablantes. Cabe destacar que en el caso de algunos hablantes latinoamericanos, la segunda persona singular cuenta con un sistema particular. Por ejemplo, en el español bonaerense Rigatuso (2011) señala que se trata de un sistema de triple dimensión funcional, en el que "vos" es un pronombre de segunda persona de confianza, "usted" corresponde a un pronombre de respeto y "tú" es usado como pronombre de segunda persona de confianza cuyo uso retrocedió frente a la generalización del voseo en distintos estilos orales y escritos, pero que actualmente emerge nuevamente como forma pronominal marcada que dinamiza la interacción conversacional.

Cabe señalar que no basta, evidentemente, solo el análisis de la fórmula de tratamiento pronominal en sí misma, sino que debe ser analizada en su conjunto con el entorno en el que se desarrolla el intercambio comunicativo. Además, las fórmulas de tratamiento que analizaremos, tal como lo hemos señalado, incluyen las verbales y nominales (Rigatuso, 2009). 


\section{Marco metodológico}

Expuesto lo anterior, en este apartado presentamos la metodología, que tiene un enfoque mixto de alcance descriptivo. En primer lugar, se señala el objetivo de la investigación y el corpus utilizado con las categorías de selección del mismo. Luego, se describen las etapas y la forma en que se realizó el análisis.

En relación al primer aspecto, la investigación reportada en este artículo tiene como objetivo principal describir las relaciones de poder/solidaridad y cercanía/distancia y el uso de la palabra autoritaria que denotan los mecanismos apelativos que se utilizan en el discurso religioso digital, analizando las diversas fórmulas de tratamiento de dos credos (católico y protestante) en un blog y un foro religiosos.

Cabe destacar que, luego de una revisión previa, se observa que la mayoría de los sitios web religiosos no han implementado la opción de participar respondiendo o comentando las entradas de blog o no incluyen foros de discusión en sus portales. Tal es el ejemplo de los sitios oficiales de los Testigos de Jehová, de los Adventistas, de los Mormones, entre otros. Sin embargo, sí es posible encontrar este tipo de instancias interactivas en algunas agrupaciones tanto protestantes como católicas, que cuentan con altos grados de diálogo entre los visitantes. Es por esta razón que para realizar este estudio nos centramos en plataformas digitales de estos dos credos.

La elección del foro y del blog estuvo guiada por cuatro criterios. En primer lugar, la representatividad en relación al credo al que pertenece, aun cuando es necesario señalar que en el contexto protestante esto es más difícil, pues estos grupos no presentan una jerarquía explícita a raíz de la multiplicidad de denominaciones que conforman este credo. El segundo criterio está asociado con la plataforma de interacción, es decir, que el blog o foro esté abierto a que cualquier usuario comente con una simple inscripción previa. Esta característica es relevante, ya que muchos blogs no dan la posibilidad de recibir comentarios libremente. El tercer criterio utilizado fue que el blog y el foro (y sus comentarios respectivos) se mantuvieran vigentes y activos hasta el momento de la recolección del corpus (noviembre, 2015), lo que le otorga mayor grado de confiabilidad a la investigación. Por último, el cuarto criterio utilizado buscó que el blog y el foro tuvieran un propósito declarado de orientación doctrinaria a sus feligreses visitantes.

Estos criterios permitieron escoger, para el caso del credo protestante, el blog Libres en Cristo (http://blog.libresencristo.org/), organización que no está adscrita a ninguna denominación religiosa particular, sino que está conformada por varias instituciones que pertenecen al mundo protestante, pero representa a una comunidad relevante en este grupo. El propósito de esta agrupación, creada en 2005, es "ayudar a los cristianos a escapar del pecado sexual para siempre". Respecto al credo católico, el foro seleccionado es Catholics de la 
Red Informática de la Iglesia en América Latina (http://foro.catholic.net/). Cabe señalar que la agrupación que está detrás del foro nació en el año 2000 para dar a los católicos un espacio de convivencia, orientación y reflexión, y este fue impulsado por el Vaticano y el Consejo Episcopal Latinoamericano.

Con el objetivo de acotar temáticamente el estudio, nos limitamos a los tópicos sobre sexualidad y relaciones de pareja, ya que son los de mayor preferencia de los visitantes, lo cual se evidencia en la gran cantidad de comentarios registrados, como ya se indicó en los apartados precedentes.

El corpus está compuesto por 10 entradas del blog protestante y 10 entradas del foro católico, formando un total de 20 entradas, junto a sus respectivos comentarios. Para el caso de los comentarios, se consideran todos los escritos hasta la fecha del análisis (noviembre, 2015). En la tabla 1 se da cuenta del desglose de los comentarios considerados en el estudio:

\section{TABLA 1}

Entradas y comentarios incluidos en el análisis

\begin{tabular}{ccc} 
CREDO & ENTRADAS (POST INICIAL) & N $^{\circ}$ DE COMENTARIOS \\
Protestantes & 10 & 204 comentarios \\
\hline Católicos & 10 & 167 comentarios \\
\hline Total & 20 & 371 comentarios \\
\hline
\end{tabular}

Una vez recolectado el corpus, se siguieron dos fases. En la primera, el procedimiento de análisis consideró el marcaje de formas de tratamiento nominales, pronominales y verbales mediante el programa de análisis cualitativo Atlas TI utilizando las categorías que surgen a partir de la discusión teórica presentada en los apartados anteriores. Estas categorías plantean dos niveles de análisis. Por una parte, los ejes de poder/solidaridad y cercanía/distancia (Brown y Gilman, 1960), que denotan la manera en que los interlocutores se relacionan entre sí. De esta forma, observamos si es que se ejerce poder o más bien si sus comunicaciones son del tipo solidario, así como algunos de los principales matices que pueden advertirse en cada caso; junto con esto, consideramos que este tipo de relaciones dialógicas son eminentemente asociadas con la distancia comunicativa, ya que no son frente a frente, sino mediadas por el computador. Por otra parte, en el nivel de autoridad (Orlandi, 2012) observamos cómo se refleja a través de las fórmulas de tratamiento la autoridad o el uso de la palabra autoritaria (Bajtín, 2011) del credo utilizando como punto de partida el post inicial y luego analizando los comentarios vinculados. En este segundo nivel se estudia, además, la presencia del poder pastoral (simbólico) que allí se articula (Foucault, 2008, 2009, 2011). En definitiva, se describen los modos que han desarrollado los credos católico y protestante para lidiar con la horizontalidad dialógica que están exigiendo los usuarios de las plataformas online (e. g., Androutso- 
poulos, 2010; Tolosa, 2011; De Souza, 2014). Cabe destacar que este marcaje no considera las variedades dialectales de los hablantes (donde, por ejemplo, existen diferencias entre voseo, ustedeo o tuteo) debido a que cuando los participantes comentan no explicitan sus procedencias geográficas ni sociales.

En la segunda fase se realizó el procedimiento de validación del análisis con dos expertos en lingüística con dominio del español como lengua materna. Luego de recibidos los formularios de cada experto, se analizaron los datos y se obtuvo un promedio de 95\% de validación. Adicionalmente, a través del software SPSS versión 21 se obtuvo un coeficiente de Kappa de Fleiss de un 0,92, lo que según Landis y Kock (1977) es un acuerdo casi perfecto.

\section{Resultados, hallazgos y discusión}

En este apartado se presentan los resultados de la investigación; en primer lugar, en términos cuantitativos, y, a continuación, la visión cualitativa. En el desarrollo de la exposición se presentan además los hallazgos y discusión por cada resultado obtenido.

\subsection{Resultados cuantitativos}

Desde el punto de vista cuantitativo, en ambos credos y tipos de plataforma, existe un mayor uso de fórmulas de tratamiento (pronombres personales y reflexivos, verbales y nominales) que denotan solidaridad del tipo T-T (tú-tú), y es escaso el uso de la forma de tratamiento de poder V-T (usted-tú). Los datos se muestran en la tabla 2.

\section{TABLA 2}

Fórmulas de tratamiento en el nuevo espacio virtual: poder y solidaridad

\begin{tabular}{cccc}
\multicolumn{2}{c}{ DIMENSIONES } & BLOG LIBRES EN CRISTO & FORO CATHOLICS \\
\multirow{2}{*}{ Pronominales } & $\mathrm{T} / \mathrm{T}$ & 130 & 23 \\
\cline { 2 - 4 } & $\mathrm{T} / \mathrm{V}$ & 1 & 1 \\
\hline \multirow{2}{*}{ Verbales } & $\mathrm{T} / \mathrm{T}$ & 130 & 213 \\
\cline { 2 - 4 } & $\mathrm{T} / \mathrm{V}$ & 1 & 5 \\
\hline \multirow{2}{*}{ Nominales } & $\mathrm{T} / \mathrm{T}$ & 114 & 69 \\
\cline { 2 - 4 } & $\mathrm{T} / \mathrm{V}$ & 11 & 1 \\
\hline
\end{tabular}

En el caso de los comentarios del blog Libres en Cristo nos encontramos con un total de 130 fórmulas pronominales de solidaridad T-T y una forma de poder T-V. Respecto al foro Catho- 
lics, observamos un total de 23 fórmulas de solidaridad (T-T) y, al igual que en el caso de los protestantes, solo una forma de poder (T-V).

En cuanto a las fórmulas verbales, en el foro católico se observaron un total de 213 del tipo solidario T-T y solo 5 del eje de poder T-V, por la relación que denotan los interactuantes. Por su parte, en el blog protestante se registraron 130 formas de solidaridad/cercanía T-T y 1 del eje del poder/distancia T-V.

En el caso de las fórmulas de tratamiento nominales utilizadas en las dos plataformas digitales — blog y foro - se pueden observar los siguientes hallazgos. Las entradas del foro católico registran un total de 69 casos de fórmulas nominales T-T, que se pueden agrupar en el eje de poder/solidaridad de acuerdo a lo que denota dicha apelación (considerando los nombres registrados por los usuarios y los tratamientos de afecto como amigo o hermano) y solo 1 caso en el que se presenta más bien el eje de poder/distancia T-V. Por su parte, en el blog protestante Libres en Cristo se observa un total de 125 formas de tratamiento nominales, divididas en 114 en el eje de solidaridad y 11 en el eje de poder.

Para una mejor representación de los datos hemos utilizado estadística descriptiva para obtener los porcentajes de cada tipo de fórmula y dimensión que se presentan en el gráfico 1.

\section{GRÁFICO 1}

Fórmulas de tratamiento en el nuevo espacio virtual: poder y solidaridad

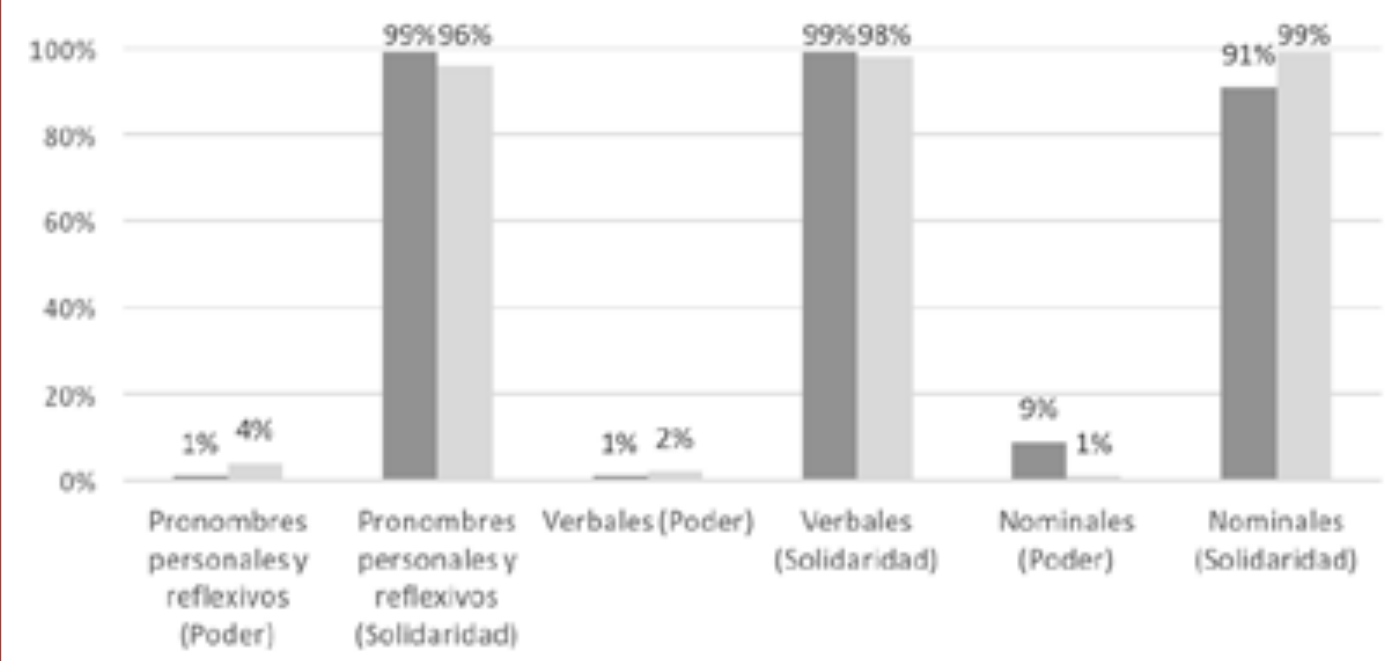

Protestantes (Blog) = Católicos (Foro)

De acuerdo al gráfico 1, se puede observar que el uso de fórmulas nominales solidarias es levemente mayor entre católicos (99\%) que entre protestantes (91\%), pero esta diferencia no es estadísticamente significativa. En los otros dos casos los resultados son muy similares. 
En términos globales, se puede sostener que tanto desde una mirada intercredo como de tipo de plataforma no hay diferencias en el tipo de fórmulas de tratamiento que se utilizan, al menos en la muestra escogida y revisada, ya que, en los tres tipos de fórmulas de tratamiento analizadas, los resultados indican que predomina la dimensión de solidaridad más que la de poder.

\subsection{Resultados cualitativos}

Siguiendo el objetivo de describir las relaciones de poder/solidaridad y cercanía/distancia y el uso de la palabra autoritaria que denotan los mecanismos apelativos que se utilizan en el discurso religioso digital, luego del análisis estadístico, a continuación, se presenta la mirada cualitativa, que evidencia los siguientes hallazgos.

\subsubsection{Eje poder/solidaridad y cercanía/distancia}

En ambos credos existe un mayor uso de pronombres personales y reflexivos, así como verbos que denotan solidaridad del tipo T-T, y es escaso el uso de la forma de tratamiento de poder V-T, que si bien no es explícita, sí puede ser interpretada a partir de la relación entre los interactuantes que se establece en el espacio virtual.

En el caso de las fórmulas pronominales de poder T-V (I), se estima que es usada más bien como una forma de distancia comunicativa o respeto y no como superioridad o jerarquía de una persona por sobre otra(s), ya que aquí el interlocutor apela al otro (al que probablemente no conoce en persona) a través de una pregunta retórica y, más que ubicarse en el eje de poder, lo que hace es ubicarse en el eje de solidaridad/distancia. Respecto al foro Catholics, en la forma de poder (T-V) que se observa, sí se puede advertir el eje de poder y distancia entre los interlocutores (2); esto porque el interlocutor establece un diálogo con el padre o sacerdote, la voz autorizada del credo, y, más que ubicarse en el mismo nivel de jerarquía, lo que hace es evidenciar una relación asimétrica del tipo V-T (sacerdote-feligrés) que ha pervivido históricamente en el discurso religioso. Esto resulta particularmente llamativo, ya que el espacio virtual público, por sus características intrínsecas que permiten la participación fluida del usuario, tiende a utilizar predominantemente un diálogo más horizontal y cercano (Androutsopoulos, 2010; Tolosa, 2011); sin embargo, en el ejemplo (2) esto no sucede, ya que el padre y el feligrés emplean la fórmula $\mathrm{V}$-T.

(1) FT_Prot_4: Esta fue una de las mentiras que al ser descubierta me dolió en lo más profundo de mí ser. ¿Usted se preguntará por qué? Pues porque esta mentira fue el cimiento de esa relación de pecado, la mayor fuente de alimento a mi ego y a mi estúpido egoísmo. 
(2) FT_Cat_1: Hola Padre: Gracias por sus anteriores mensajes; me están ayudando mucho. Quisiera que usted me aconsejara algo para poder adquirir la castidad, porque verdaderamente me cuesta bastante, y hay momentos en que me resulta muy difícil. Le agradezco lo que pueda hacer por mí. Ed.

Respuesta: Estimado Ed.: Lo importante es que sepas que la castidad es posible.

En cuanto a las fórmulas verbales, tanto en el foro católico como el blog protestante -como se expuso en los datos cuantitativos - predomina la dimensión de solidaridad, ya que la mayoría de los comentaristas, ya sea en blog o foro, se refiere a sus interlocutores como si no hubiera diferencias sociales, etarias, culturales, etc., salvo contadas ocasiones, es decir, se ubican en el eje solidaridad/cercanía. Además, en ambas plataformas los interactuantes frecuentemente se entregan consejos y orientaciones sobre las temáticas discutidas para mantener las verdades y designios de los credos, tal como lo muestran los ejemplos (3) y (4). En este sentido, se podría sostener que actualmente los comentaristas pueden ser consejeros o guías, de la misma manera como lo haría un pastor o un sacerdote en la confesión privada, en que el diálogo entre estos interactuantes es eminentemente más horizontal y simétrico tanto en foro como en blog.

(3) FT_Cat_10: Estás pasando por una mala racha, pero persiste en la fe. Quien persiste en la fe sabe amar de verdad $[\ldots]$

(4) FT_Prot_3: ¿Has examinado en tu interior qué es lo que REALMENTE buscas de otro hombre cuando lo deseas?

En el ejemplo (3) del foro del credo católico, el emisor orienta y anima a un interlocutor afligido (autor de la publicación inicial) porque no encuentra pareja, para que persista en la fe y que deje en manos de Dios la posibilidad de este vínculo, actuando como un consejero, pero empleando elementos verbales de solidaridad y cercanía, con un tono amistoso, que el receptor responde de la misma forma, generándose una relación T-T. En el ejemplo (4) del credo protestante, uno de los administradores del blog (en el texto le invita a leer una nota en "nuestro sitio" para ampliar su consejo) incita a reflexionar a otro que ha confesado ser homosexual (un pecado muy condenable dentro de este credo), con el objetivo de corregirlo de la atracción hacia su mismo sexo. El locutor realiza una pregunta de manera simétrica, empleando verbos solidarios en estilo cordial, que además denotan cercanía, lo que indicaría que no pretende condenar su pecado, sino comprenderlo y conducirlo por la senda que exigen los preceptos bíblicos. Los receptores le responden de la misma manera, produciéndose, al igual que el ejemplo anterior, una relación T-T.

Estas fórmulas de tratamiento presentes en el escenario tecnológico y en un espacio de interacción virtual evidencian mayor grado de solidaridad. Lo anterior se representa en la figura 2 a través de los ejes planteados por Brown y Gilman (1960). Así, el bloguero y el ad- 
ministrador de foro utilizan fórmulas de tratamiento que se ubican en el eje de solidaridad y distancia de la propuesta de los autores. De esta manera, observamos que la tarea de guía espiritual, que antes era predominantemente ejercida por el sacerdote o pastor, donde la relación era más bien $V$-T, en la comunidad virtual pasamos a una relación del tipo T-T, ya que los interactuantes están situados en el eje de solidaridad.

\section{FIGURA 2}

Fórmulas de tratamiento en el nuevo espacio virtual

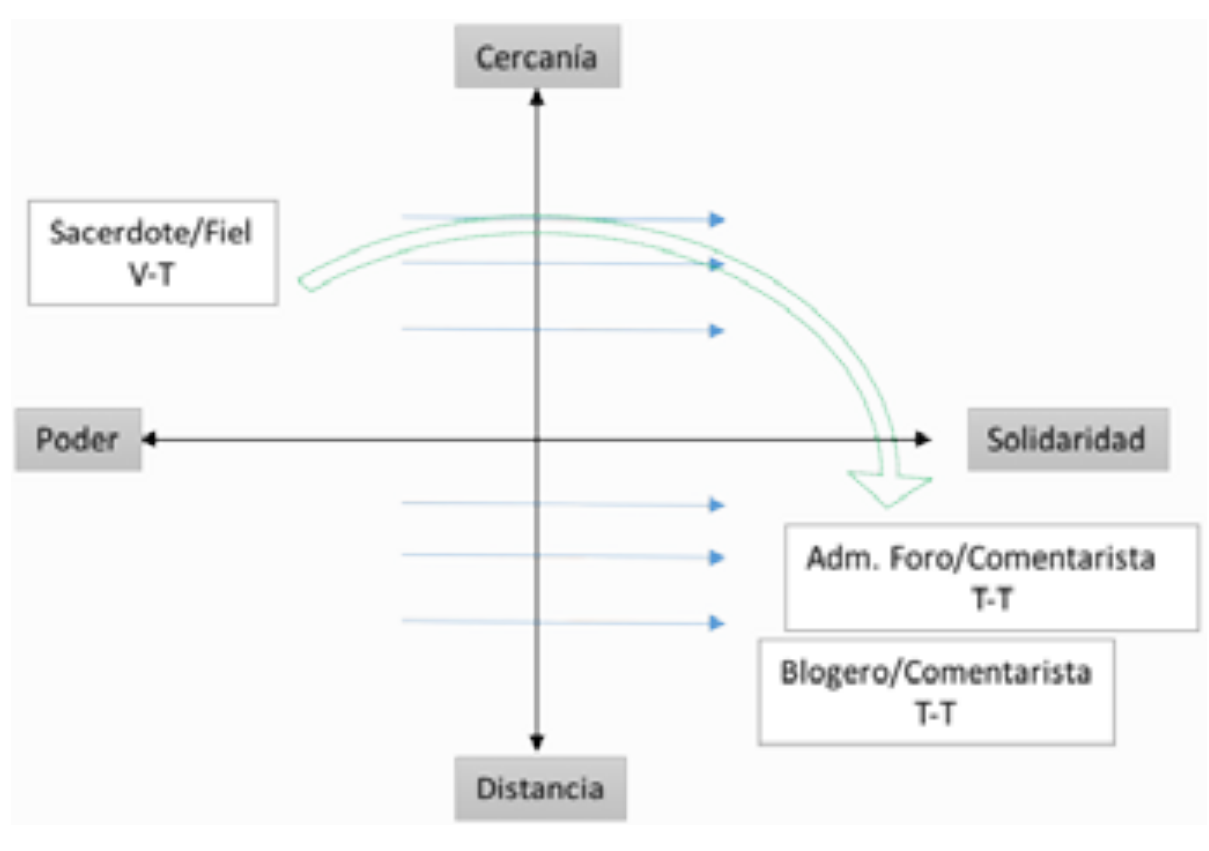

Este hallazgo de la investigación podría ser explicado por el espacio digital en que se produce el diálogo, es decir, en las plataformas tecnológicas (blog y foro) seleccionadas en este estudio. Dado que esta interacción comunicativa es mediada por computador, no es posible el contacto (cara a cara) entre los participantes y, por tanto, aquellos elementos culturales e históricos que antes denotaban jerarquía y distancia, como, por ejemplo, la edad, la formación académica, la vestimenta, entre otras, se diluyen en este espacio, ya que no se sabe con certeza quién está del otro lado del computador. Esta ausencia de contacto físico genera que se solidaricen aún más las formas de tratamiento entre los interlocutores, tanto del blog como del foro, porque al parecer se asume que el que está al otro lado está al mismo nivel social, cultural, etario, etc.

En el caso de las fórmulas de tratamiento nominales utilizadas en las dos plataformas digitales - blog y foro- se pueden observar los siguientes hallazgos. En el caso del foro católico existe un total de 69 usos de solidaridad/cercanía (considerando los nombres registrados por los usuarios y los tratamientos de afecto como amigo o hermano) y solo a caso en el que 
se presenta más bien el eje de poder/distancia T-V. En el ejemplo (5), del foro católico, se evidencia una fórmula de tratamiento nominal solidaria T-T, ya que un interlocutor expresa una aflicción al grupo y otro lo interpela con afecto a través de un trato amistoso que incluso se desplaza hacia el eje de mayor cercanía.

Cabe recordar que Bravo (2003) plantea una taxonomía de dos tipos de imagen social que utilizan los sujetos; por un lado está la "afiliación” y, por otro lado, la "autonomía”. La "afiliación" pretende identificar a las personas con las cualidades del grupo, mientras que la "autonomía" se refiere a los comportamientos mediante los cuales un integrante de un grupo adquiere un "contorno propio" dentro del mismo. Ambas son categorías vacías que solo cobran sentido en el uso social y cultural de un grupo. Por lo tanto, el trato cercano que se presenta posteriormente al incluir el tú en el nosotros evidencia la "afiliación" (Bravo, 2003) del interlocutor con relación a César.

(5) FT_Cat_8: Querido César. No pases solo esta noche oscura! Nos tienes a todos para compartir esos momentos y no solo los tiempos de gracia.

Por su parte, en el blog protestante Libres en Cristo, del total de 125 formas de tratamiento nominales, 72 son apelaciones al participante en su comentario (recordemos que es necesario usar un nombre que no se sabe si es real o un seudónimo para realizar un comentario), como muestran los ejemplos:

(7) FT_Prot_1: Excelente artículo Chema !!!

(8) FT_Prot_7: Gracias por tu correo Ramiro

Este alto número de uso de formas nominales, empleadas tanto por el autor del blog como por los comentaristas, denota la solidaridad existente en esta instancia comunicativa, al igual que en el foro católico. Respecto al resto de las formas nominales del blog Libres en Cristo, se observan 42 de cercanía (querido, estimado, amigos, hermanos, etc.), que contribuyen a aumentar la solidaridad entre los participantes (9), y 11 de poder (pastor, padre, maestro, señor, etc.), que son empleadas para dirigirse tanto a la comunidad del blog como a participantes individuales (10).

(9) FT_Prot_8: mis hermanos los animo a que sigamos confiando en nuestro Señor Jesús

(10) FT_Prot_9: Señor mío, uno de los principios más importantes que jamás aprenderé sobre la vida en el Espíritu contra la vida en la carne se encuentra en Romanos 8:5

Las formas nominales de poder son escasas, pero consideramos que es relevante resaltarlas, toda vez que, cuando nos referimos a las formas nominales padre, pastor, maestro, señor, decimos que estas tradicionalmente han sido parte de la combinación $\vee$-T, donde el pastor 
recibía $V$ y el fiel recibía T. Estas formas se asociaban al eje de poder/cercanía, las cuales todavía persisten, pero si lo observamos en esta situación de comunicación digital se dan con mucho menos frecuencia.

Respecto a esto último, cabe destacar una leve diferencia entre ambos medios (foro católico y blog protestante) porque en el caso del blog se presenta una mayor cantidad de formas nominales V-T, lo cual podría evidenciar más verticalidad en la comunicación del blog protestante que en el foro católico, es decir, existirían participantes con cierta jerarquía y otros subordinados, puesto que el bloguero, en su función de representante de la voz de Dios, vela por que el diálogo se mantenga dentro de los preceptos cristianos. Esto podría ser explicado por la idea de Martínez (2007) en que el blog es un espacio personal en que solo existiría un protagonista, en este caso, el representante de la voz de Dios. En el caso del foro católico, por otro lado, habría mayor libertad comunicativa, por lo cual la subordinación, por lo tanto, las relaciones de poder, serían menos frecuentes, lo que concuerda con las ideas de Gouti (2006) y Pano $(2008,2009)$. Estos resultados podrían ser más interesantes si existiera información acerca de quiénes son los administradores reales de ambos medios (sacerdotes, pastores, etc.), lo cual no es declarado dentro de las condiciones de participación.

Respecto al alto grado de cercanía con que se relacionan los interlocutores del foro y del blog mediante las formas de tratamiento nominales empleadas, una posible explicación podría estar vinculada a las propiedades del contexto tecnológico en el cual se encuentran, así como a sus intenciones (Crystal, 2001; Yus, 2001). En este sentido, el blog está orientado a formar comunidad entre autores y comentaristas con una temática particular desde la cual se articula, controlado muchas veces por el autor (Orihuela, 2006; Pano, 2009), mientras el foro busca discutir tópicos entre interactuantes, pero no necesariamente es uno el que lidera el tema; además, generalmente se busca persuadir de un tópico una vez resuelto el debate o la pregunta inicial (Gouti, 2006). Esto se condice con los planteamientos de Orihuela (2006), quien indica que en el blog la interacción es restringida y dirigida por el locutor que propone el tema; por lo tanto, es más bien vertical; en cambio, en el foro tiende a ser horizontal y abierta.

Por último, los resultados de las formas de tratamiento nominales concuerdan con la propuesta de Cantamutto y Vela Delfa(2016) de que existirían ciertas características compartidas en el discurso digital y que estos rasgos variarían dependiendo de las propiedades del tipo de discurso digital; en nuestro caso el grado de cercanía en las formas de tratamiento nominales varía si la plataforma es un blog o un foro, aun cuando dicha variación no es estadísticamente significativa.

\subsubsection{Eje de autoridad (poder pastoral/simbólico)}

En cuanto al segundo nivel de análisis, en que se busca observar la relación entre el post inicial y los comentarios en cuanto a si se mantiene la voz de Dios autorizada a través de las 
fórmulas de tratamiento, los hallazgos indican que en el caso del blog protestante Libres en Cristo se registra una importante presencia del eje de autoridad (voz autorizada por Dios) en el post inicial, así como también en los comentarios, a diferencia de lo que sucede en el foro Catholics. Mediante las formas de confianza (11 y 12) utilizadas, el autor se sitúa por encima del lector (poder pastoral del cual ha sido investido), cuando enuncia su tema en discusión (entrada principal) y le señala al interlocutor si cree que puede controlar su pecado, situándolo como un feligrés que debe luchar contra la tentación (11), o bien en el ejemplo (12), en que anima al seguidor a ser constante.

(11) FT_Prot_2: Te dejo con algunas preguntas para reflexionar; ¿Crees que puedes controlar tu pecado?

(12) FT_Prot_5: Te animo a hacerlo, es un trabajo diario y requiere que seamos intencionales.

También, el bloguero (la voz autorizada de Dios) se ubica en el eje de autoridad más adelante, cuando interrumpe los comentarios de la cadena corrigiendo ciertas nociones, ideas y creencias que no se encuentran en la línea doctrinal en la cual están circunscritos, como:

(13) FT_Prot_7: si tu no crees en la palabra de Dios como la verdad unica y absoluta lo siento mucho pero no comprenderas estos articulos (sic)

En esta respuesta, el administrador le expresa directamente al comentarista que debe regirse por los preceptos bíblicos si es que desea participar, lo cual nos remite a la noción de autoridad referida por Orlandi $(1996,2012)$. Encontramos, también, en cuanto a formas verbales y nominales, el fuerte control ejercido por la figura autoritaria en el blog protestante, que incluso puede llegar hasta la censura:

(14) FT_Prot_6: @Soñador, Publicamos todo comentario que contribuya a quien desea dejar la homosexualidad [...] si lo que deseas es solo una confrontación "ciencia vs. religión”, mejor busca otro espacio online para hacerlo.

La entrada (14) del comentarista referido por el moderador no aparece en el blog, por lo cual se deduce que sus palabras, al estar fuera del contexto exigido por el blog Libres en Cristo, fueron suprimidas. En este sentido, los moderadores de este tipo de instancias comunicativas digitales pueden "restringir las opciones de interacción de los otros usuarios en este lugar" (Cautín-Epifani, 2015: 63).

En el caso del foro católico se registra una baja presencia del uso de la autoridad en el post inicial y también en los comentarios. El post inicial, por lo general, es planteado por un usuario registrado que no necesariamente es un representante oficial del credo (puede ser cualquier persona). El comentarista expone un tópico que es de interés para él; sin embargo, 
no es el comentarista el que modera los intercambios, sino que es el que recibe el consejo y apoyo (15).

(15) FT_Cat_4: Últimamente he tenido una gran curiosidad por probar la marihuana [...] El punto es que solo quiero que alguien me explique si fumar marihuana ocasionalmente es en verdad dañino [...]

Los restantes participantes del foro católico entregan sus opiniones en un tono de cercanía que se observa principalmente por el uso del pronombre del tipo T-T (16 y 17) y por lo que se denota de la relación entre los interactuantes, ya que el post inicial podría ser considerado como la voz autorizada y, luego, los comentaristas comienzan a aconsejar a este locutor en un tono de cercanía y solidario.

(16) FT_Cat_4: Si tú tomas marihuana, te vas a terminar convirtiendo en un esclavo.

(17) FT_Cat_4: Lo "transporto" a otro ejemplo: supongamos que te agarrás una borrachera sola en tu vida $[\ldots]$

Mediante estas formas de tratamiento entre los interactuantes que denotan menor grado de autoridad, el bloguero o administrador del foro se sitúa al mismo nivel del lector-participante, como un par, como un amigo. En este caso, el poder pastoral (Foucault, 2009, 2011) está guiado por el comentarista, es decir, se podría sostener que existe la potencialidad de ejercer el rol de guía pastoral por parte de cualquier usuario en el foro, un cambio sustancial en relación al blog protestante en que el poder simbólico no es cedido por el bloguero. En síntesis, en los comentarios del foro católico la palabra autoritaria no se impone, ya que el autor del post inicial permite a los usuarios registrados generar nuevos temas sin mayor intervención o censura.

\section{Conclusiones}

Como se ha expuesto, el discurso religioso ha sido caracterizado tradicionalmente por ser del tipo autoritario y vertical (Orlandi, 1987, 1996, 2012; Bajtín, 2011). Sin embargo, en el marco del surgimiento de las nuevas instancias interactivas digitales, los hallazgos aquí presentados muestran que están emergiendo rasgos horizontales en el uso de las fórmulas de tratamiento entre los interactuantes (principalmente uso de pronombres y nombres concordantes con el esquema solidario/cercano para hablantes del español), lo que afecta la principal propiedad del discurso religioso, que es el ser autoritario y vertical. En estas nuevas plataformas estudiadas, podemos observar que en la construcción del discurso ya no existe un solo interlocutor poseedor de la palabra (como en el caso de otros discursos religiosos como el sermón), sino que es una comunidad abierta la que lo hace posible. 
También podemos concluir que la mayor horizontalidad comunicativa (Tolosa, 2013) que se ve reflejada, principalmente, en el foro Catholics da paso a que comiencen a emerger nuevos representantes que velan y cuidan la voz de Dios, pero desde una perspectiva más bien solidaria, es decir, ejercen un tipo de poder pastoral nuevo, más cercano, más horizontal. Lo anterior se debe a que ya no solo es el representante de Dios el que ejerce su poder a través del uso discursivo, sino que los participantes de un foro tienen la capacidad de orientar y de tomar la voz divina como propia para generalmente aconsejar al que está en problemas. Por tanto, la figura de autoridad es desdibujada y el feligrés común toma un rol más protagónico, lo cual sería una de las características particulares del discurso religioso digital a diferencia del discurso religioso tradicional. Esto también ocurre parcialmente en el blog, pero es más débil su aparición en las interacciones.

Entre el blog protestante y el foro católico, el primero resguarda más el predominio de la autoridad en el discurso; en el foro el ejercicio del poder simbólico no es tan evidente. Lo anterior estaría determinado por las características propias de cada dispositivo (blog y foro) $y$, por tanto, nuestros hallazgos son particulares a estas plataformas comunicativas digitales y no se extienden necesariamente a otras plataformas (Crystal, 2001; Orihuela, 2006). En este sentido, cabe destacar que sería interesante ampliar esta investigación a un mayor número de blogs y foros de ambos credos para determinar si es que el resguardo de la voz autoritaria está asociado solo a la plataforma de interacción misma o también es predominante en un credo en particular, lo cual determinaría que alguna de las dos agrupaciones religiosas se encuentra más resistente a entregar el poder de la palabra a sus comunidades virtuales.

Además, los hallazgos nos permiten sostener que efectivamente los nuevos dispositivos digitales han modificado las prácticas discursivas en términos del uso de fórmulas de tratamiento solidario, lo que concuerda con el análisis pretecnológico que proponían Brown y Gilman (1960) y también sigue la tendencia del estudio de Cautín-Epifani (2015).

Estas conclusiones plantean nuevos desafíos para quienes lideran los credos religiosos en un mundo predominantemente digital, pues de alguna manera se está reconfigurando el discurso otrora autoritario, ya que en el nuevo espacio público virtual los intercambios comunicativos se vuelven cada vez más horizontales al aumentarse las posibilidades de que los usuarios no investidos por las instituciones estén haciendo un uso cada vez más legitimado de la voz divina. Esto concuerda con la idea de deslegitimación del rol de la autoridad en la red expuesta por Tolosa (2011, 2013), en que el espacio virtual ha modificado diversos tipos de relaciones mediatizadas volviéndose más horizontales y menos autoritarias, y con la idea de Androutsopoulos (2010) de que la web presenta una infraestructura en la que es posible apropiarse y construir la mayor parte del contenido.

También, queremos señalar que en el transcurso de la investigación se presentaron limitaciones principalmente en el tamaño de la muestra del corpus, ya que fue difícil ubicar foros 
y blogs que fueran representativos de sus respectivos credos religiosos, lo que impidió incluir una mayor cantidad de entradas en el corpus. Asimismo se evidencia la necesidad futura de incorporar entrevistas a los participantes de foros y blogs, ya que esto podría contribuir a mejorar la interpretación de los datos en términos de rasgos socioculturales de los interactuantes, aspecto al que no ha sido posible acceder solo desde las entradas y comentarios de foros y blogs.

Finalmente, las proyecciones de este estudio implican avanzar hacia otras plataformas utilizadas por el discurso digital como Twitter o Facebook, y seguir caracterizando el discurso religioso a través de nuevos niveles discursivos de análisis, como, por ejemplo, el enfoque multimodal.

\section{Bibliografía citada}

AceBAL, Martín, 2002: "La construcción discursiva de la identidad católica en las homilías de la línea tradicional de la Iglesia católica santafesina”, Texturas 2 (2), 21-30.

AceBAL, Martín, 2006: "La paráfrasis del texto bíblico en la homilía católica. Aportes al género y variaciones de su realización”, ponencia presentada en el Congreso Internacional Transformaciones Culturales: Debates de la Teoría, la Crítica y la Lingüística, Universidad de Buenos Aires, Buenos Aires.

Androutsopoulos, Jannis. 2010. "Localizing the Global on the Participatory Web" en Nikolas CouPLAND, (ed.): The Handbook of Language and Globalization, Sussex: Wiley-Blackwell, 201-231.

Arnoux, Elvira, 2004: "La reformulación interdiscursiva en Análisis del Discurso" en Actas del IV Congreso Nacional de Investigaciones Lingüísticas y Filológicas Análisis del Discurso y Enseñanza de la Lengua, Lima: Universidad Ricardo Palma.

Bajtín, Mijaíl, 2011: Las fronteras del discurso, Buenos Aires: Las Cuarenta.

Bonnin, Juan Eduardo, 2010: "Los géneros discursivos en la estrategia del episcopado católico argentino. Aspectos políticos del discurso religioso entre el autoritarismo y la democracia (1965-1990)", Revista Signos 43 (72), 9-30.

Bonnin, Juan Eduardo, 2006: "Posiciones y posicionamientos: Análisis comparativo de discursos religiosos y políticos”, Revista Virtual de Estudos da Linguagem 4 (6), 1-24.

Bravo, Diana. 2003. "Actividades de cortesía, imagen social y contextos socioculturales: una introducción" en Diana Bravo (ed.): Actas del I coloquio del Programa EDICE: La perspectiva no etnocentrista de la cortesía: identidad sociocultural de las comunidades hispanohablantes, Estocolmo: Universidad de Estocolmo, 98-108. 
Brown, Roger, y Albert GILMAn, 1960: "The pronouns of power and solidarity" en Thomas Sebeok (ed.): Style in Language, MIT Press: University of Michigan, 253-276.

Calderón, Miguel, 2010: “Formas de tratamiento" en Milagros Aleza Izquierdo y José María EnGUITA (coords.): La lengua española en América: normas y usos actuales, Valencia: Universitat de Valencia.

Cantamutto, Lucía, 2011: "La conformación de un corpus de mensajería de texto: la interacción mediada digitalmente" en Actas de las IV Jornadas de Investigación de Humanidades. Homenaje a Laura Laiseca, Bahía Blanca: UNS.

Cantamutto, Lucía, y Cristina Vela, 2016: "El discurso digital como objeto de estudio: de la descripción de interfaces a la definición de propiedades", Aposta. Revista de Ciencias Sociales 69, 296-323.

Cautín-Epifanı, Violeta, 2015: "Poder virtual y formas de tratamiento en el discurso mediado por computadora: exploración de una red comunicativa virtual”, Forma y Función 28 (1), 55-78.

CRYSTAL, David, 2001: Language and the internet, Cambridge: Cambridge University Press.

Da SILva, Tatiane, e Ivandilson Costa, 2011: "O discurso religioso: Aspectos de performatividade, autoritarismo e relacões de poder”, Linguagem-Estudos e Pesquisas 15 (2), 119-136.

De SouzA, Ronivaldo, 2014: "O discurso religioso na mídia digital: entre a diversidade e a intransigencia”, Revista Eletrônica de Teologia e Ciências das Religiões 1, 98-110, [disponible en http://revista.faculdadeunida.com.br/index.php/unitas].

Edeso, Verónica, 2005: “Usos discursivos del vocativo en español”, Español Actual: Revista de Español Vivo 84, 123-142.

Edeso, Verónica, 2012: El vocativo en español. Definición, características y combinatoria, Madrid: Círculo Rojo.

Eliade, Mircea, 1998: Lo sagrado y lo profano, Barcelona: Paidós.

FAYE, Cleide, 2007: "Discurso religioso: funções e especificidade", Soletras 13, 38-45.

Fontanella de Weinberg, María Beatriz, 1999: "Sistemas pronominales de tratamiento usados en el mundo hispánico” en Ignacio Bosque y Violeta Demonte (eds.): Gramática descriptiva del español, Madrid: Espasa Calpe, 1420-1424.

Foucault, Michel, 2008: Historia de la sexualidad I. La verdad de saber, Buenos Aires: Siglo XXI Editores.

Foucault, Michel, 2009: Seguridad, territorio, población, Buenos Aires: Fondo de Cultura Económica. 
Foucault, Michel, 2011: Los anormales, Buenos Aires: Fondo de Cultura Económica.

Goutı, Gérard, 2006: "Intercambios en los foros de debate: algunos elementos de reflexión para un acercamiento lingüístico", Estudios de Lingüística del español 24 [disponible en http:// elies.rediris.es/elies24/gouti.htm].

Hummel, Martin, 2010: "Reflexiones metodológicas y teóricas sobre el estudio de las formas de tratamiento en el mundo hispanohablante, a partir de una investigación en Santiago de Chile" en Martin Hummel, Bettina Kluge y María Eugenia Vásquez (eds.): Formas y fórmulas de tratamiento en el mundo hispánico, México: El Colegio de México, 79-100.

LANDIS, Richard, y Gary Kock, 1977: "The measurement of observer agreement for categorical data", Biometrics 33, 159-174.

Maingueneau, Dominique, y Frédéric Cossutta, 1995: "L'analyse des discours constituants”, Langages 29 (117), 112-125.

Martínez, José Manuel, 2007. "El blog como fenómeno semiótico", Revista Electrónica de Estudios Filológicos 13 [disponible en https://www.um.es/tonosdigital/znum13/secciones/ estudios_R_blog.htm].

Orinuela, José Luis, 2006: La revolución de los blogs, Madrid: La esfera de los libros.

Orlandi, Eni, 1987: Palavra, fé, poder, Campinas: Pontes.

Orland, Eni, 1996: A linguagem e seu funcionamento: as formas do discurso, Campinas: Pontes.

Orlandi, Eni, 2012: Análisis de discurso. Principios y procedimientos, Santiago de Chile: Lom.

PAno, Ana, 2008: Dialogar en la Red. La lengua española en chats, e-mails, foros y blogs, Nueva York: European University Studies.

Pano, Ana, 2009: "Diálogo y lengua española en contextos de comunicación mediada por ordenador" [disponible en http://amsacta.unibo.it/2547/1/Pano_Dialogar_Red.pdf, fecha de consulta: 10 de enero de 2016].

Placencia, María Elena, 2015: "Yahoo! Respuestas como columna de consejos: Algunos rasgos de un género híbrido" [disponible en http://edice.org/biblioteca/601-2101-2-PB.pdf, fecha de consulta: 30 de mayo de 2017].

RIDAO, Susana, 2014: "Análisis discursivo de las enfermedades ataxia y esclerodermia en Youtube: Una aproximación a las estrategias de (des)cortesía" en María Eugenia Flores y José María INFANTE (eds.): La(des)cortesía en el discurso: perspectivas interdisciplinarias (imagen, actos de habla y atenuación), Monterrey-Estocolmo: UANL-EDICE, 85-109. 
Rigatuso, Elizabeth, 2000: “'Señora (...) ¿No tenés más chico?’ Un aspecto de la pragmática de las fórmulas de tratamiento en español bonaerense”, Revista Argentina de Lingüística 16, 293-344.

Rigatuso, Elizabeth, 2006: "Migraciones, lengua e identidad" en Pedro Luis Barcia (org.): III Congreso Internacional de la Lengua Española: Identidad Lingüística y Globalización, Buenos Aires: Academia Argentina de Letras.

Rigatuso, Elizabeth, 2009: “'A su merced... de su más humilde hijo’. Asimetrías e identidades en construcción: fórmulas de tratamiento y cortesía verbal en el español de Buenos Aires de la etapa colonial”, Boletín de la Academia Argentina de Letras 73, 349-412.

Rigatuso, Elizabeth, 2011: “‘De Vos, de Tú, de Usted?’ Gramática, pragmática y variación: hacia una reinterpretación de los pronombres de tratamiento en español bonaerense" en Leticia Rebollo Couto y Celia Regina dos Santos López (orgs.): Las formas de tratamiento en español y en portugués, Rio de Janeiro: Editora da UFF, 381-407.

Rost, Alejandro, 2004: “Pero, ¿de qué hablamos cuando hablamos de interactividad?” [disponible en http://s3.amazonaws.com/lcp/alaicinternet/myfiles/Alejandro\%20Rost\%20\%28Argentina\%29.pdf, fecha de consulta: 10 de enero de 2016].

SCOLARI, Carlos, 2008: Hipermediaciones. Elementos para una teoría de la comunicación digital interactiva, Barcelona: Gedisa.

Tolosa, Mauricio, 2011: “Las redes sociales y el desplome de la pirámide” [disponible en http:// sitiocero.net/2011/las-redes-sociales-y-el-desplome-de-la-piramide/, fecha de consulta: 10 de enero de 2016].

Tolosa, Mauricio, 2013: Comunidades y redes sociales. El desplome de las pirámides, Santiago: Papyrbit Editores.

VARAS, Magaly, y Cristián GonzÁlez, 2016: "Interactividad en sitios web de medios: buscando nuevas formas de diálogo con sus usuarios", Estudios sobre el Mensaje Periodístico 22 (2), 549-566.

VILCHES, Lorenzo, 2001: La migración digital, Barcelona: Gedisa.

VitalE, Alejandra, 2003: "Control de la lectura y reformulación en el 'Evangelio en Solentiname' de Ernesto Cardenal”, ponencia presentada en el I Coloquio Argentino de la IADA, Universidad de La Plata, La Plata.

Yus, Francisco, 2001: Ciberpragmática. El uso del lenguaje en internet, Barcelona: Ariel. 